\title{
Some Cases of Uterine Fibroid Associated with Pregnancy. ${ }^{1}$
}

\author{
By James Phillips, F.R.C.S.E., \\ Hon. Surgeon, Bradford Royal Infirmary.
}

THE following cases of uterine fibroids plus pregnancy are of interest chiefly as illustrations of the conditions which may call for surgical interference.

Pregnancy occurring in a uterus which contains one or more fibroids is a condition which renders the patient liable to a number of dangers either before, at, or after her confinement. So much is this so that some gynæcologists recommend hysterectomy whenever the condition is diagnosed. During the pregnancy the chief dangers are ( 1 ) miscarriage due to the fibroid interfering with the proper expansion of the uterus, and (2) red degeneration of the tumour with liability to infection of the degenerated growth. During labour there is danger of (I) obstruction to labour by impaction of a fibroid in the pelvis, (2) mechanical interference, by an intra-mural fibroid, with the normal muscular contraction, leading to delayed delivery, retained placenta or post partum hæmorrinage. In the puerperium infection of a degenerating fibroid is the chief danger.

We rarely have the opportunity to diagnose the presence of a fibroid prior to the onset of labour unless and until some complica. tion arises as in the two following cases.

CASE 1. Necrobiosis of Fibroid. Mrs. T., aged 33, came to see me on September $5^{\text {th, }}$ 1914. Menses began at 15 , always profuse. Married $6 \frac{1}{2}$ years, has avoided pregnancy. Three years ago began to get attacks of colicky pain in the abdomen quite low down. Became costive; previously bowels rather loose. Gradually increasing dyspareunia. Lately a feeling as if something was in the vagina, noticed, c.g., on sitting down. She decided to try whether pregnancy would relieve her symptoms and she became pregnant three months ago. Since then all her symptoms have been aggravated and frequent dysuria added. On examination the uterus was felt reaching half way to the umbilicus. P.V., cervix soft, placed high up and to the right. What appears to be a cervical fibroid growing into the right broad ligament and the size of a large pear, comes

I. A paper read at the meeting of the Bradford Medical-Chirurgical Society in February, I9I5. 
down to within two inches of the vulva. At the Bradford Royal Infirmary I opened her abdomen and was able to shell a fibroid out of the posterior wall of the uterus without disturbing the pregnancy. The pathologist reported the tumour to be undergoing red degeneration. The patient did well but would not rest after she left the infirmary and she aborted some $2 \frac{1}{2}$ months after the operation.

CASE II. Suppuration in Fibroid. Miss B., æt. 37, was sent to the Bradford Royal Infirmary on August 2, 1914, with an abdominal tumour. Her doctor had first seen her ten days before and the tumour had got markedly larger in the course of a week. The patient had had three months' amenorrhœea and had suspected pregnancy. She was thin and obviously ill; temperature Ior $^{\circ}$, pulse i 24. The abdomen showed a smooth, globular, tender, fixed, centrally placed tumour extending up to $I \frac{1}{2}$ inches above the umbilicus and closely connected with the uterus, as made out on bimanual examination. The cervix was not conclusive of pregnancy. I thought the case was one of ovarian cyst with twisted pedicle. On opening the abdomen I came on adherent omentum. On freeing this pus poured out in quantity. The bowel was packed off and the tumour delivered and found to be a uterus with a large broken-down fundal fibroid riddled with suppurating tracks. Subtotal hysterectomy was rapidly performed, the peritoneal cavity mopped out, a large rubber tube put in and the abdomen closed.

On opening the uterus a three months' pregnancy was found, and there was pus about that part of the fotal membranes which was in contact with the fibroid. The patient did well for a fortnight and then got intestinal obstruction from adhesions of small bowel to the pelvic scar. These were freed at a second cœliotomy after which she made an uninterrupted recovery.

A question (which would have been awkward from a medicolegal point of view had the patient died and which I must leave unsolved) is what was the source of the suppuration? Had the patient been using some infected instrument in an attempt at procuring abortion? Or had the pregnancy (as in Case I) interfered with the adequate blood supply of the fibroid and led to its degeneration and subsequent infection from the bowel?

In the other four cases the fibroid was not discovered until the pregnancy had terminated.

Case III. Necrobiosis during Puerperium. Mrs. A., aged 36, was delivered with forceps and made a good recovery until the 12 th day when the temperature and pulse rate went up. The patient felt well, but for a fortnight the pulse kept over roo and the temperature was never under $100^{\circ}$ in the evening, and the fundus 
uteri remained palpable above the pubes. An anæsthetic was given and on bimanual examination with a finger in the uterus a round mass some three inches in diameter was felt high up in the anterior uterine wall. The temperature came down to normal within a day of the examination and the pulse rate became steadily less. Operation was declined and the patient got quite well. Two years later she was delivered of a second child and made a perfectly normal recovery. Her second pregnancy and puerperium were watched by her medical attendant with some anxiety, but nothing abnormal occurred, nor was the tumour made out post partum.

Presumably it had become shrivelled and contracted as the result of the degeneration which followed the first pregnancy and had lost all power of growth.

CASE Iv. Sloughing of Fibroid during Puerperium. Mrs. K., who had previously had two normal confinements, was delivered on June 12, 19ro, of an anencephalic monster. There was a marked degree of hydramnios, the uterus contracted badly, the placenta had to be removed manually, and there was some post partum hæmorrhage. In spite of this she was up and about in a fortnight, but a week later she sent for her doctor because she had pain and offensive vaginal discharge. I saw her on July 7 th. She looked ill, her temperature was raised and her pulse quick. The abdomen was normal. P.V. the widely dilated cervix was found tightly surrounding a dark offensive globular mass as big as a man's fist. I thought this was an inverted uterus but on operating next day it turned out to be a sloughing fibroid which the uterus was in process of extruding. It was easily removed; the patient was soon quite well.

CASE v. Malignant Change in Fibroid. Mrs. P., æt. 40, has had two children. The second child was born ten years ago and her doctor found a fibroid in the uterus at that time. When menstruation returned it was very profuse, and a year after the confinement she was curetted with temporary benefit. For nine months before I operated on her she had had almost daily bleeding with monthly exacerbations. The uterus, which was about the size of a large cocoanut, was removed on May 16, 1914. The microscopical report was : "Hæm-angio-endothelioma, malignancy probably only slight." The patient has remained well until now (February 1915).

CASE vi. Puerperal Degeneration of Fibroid producing Intestinal Obstruction. Mrs. B., æt. 35, was confined on December 23, 1914. Her doctor found a fibroid in the anterior wall of the uterus 
at the time. The puerperium was normal, save for rather more abdominal pain than usual, until the early morning of December $3^{\text {rst }}$ when she vomited and the nurse found that the abdomen had become suddenly and markedly distended. An enema was given; no motion was passed but a good deal of flatus. The same result followed a second enema in the late afternoon. When I saw her at 9 p.m. the patient did not look ill and had little pain and was not sick. The temperature was normal; the pulse rate Iro. There was very considerable tympanitic abdominal distension and some slight general tenderness. P.V. nothing abnormal was made out and the uterus was apparently involuting well. On opening the abdomen coils of small bowel were found adherent to a fibroid in the anterior uterine wall. It was as big as a cricket ball and of greyish-yellow colour, "boggy" in consistence, and its peritoneal coat disintegrated in places. There was some opaque odourless fluid in the neighbourhood. The adherent bowel was separated and subtotal hysterectomy performed. She made an excellent recovery, save for the occurrence of a small anal abscess in connection with an inflamed pile which had to be incised on the 8th day after the operation. She was sitting out of bed less than three weeks after the hysterectomy had been done and was soon quite well.

If I were asked to lay down guiding principles for the treatment of cases in which pregnancy is associated with fibroids, I think I should say something like this. Many patients with fibroids have perfectly normal pregnancies, labours and puerperia and therefore I cannot agree that hysterectomy is advisable in every case. I recently removed a fibroid from a woman aged 48 who had had nine living children.

If a pregnant woman is known to have a fibroid she should be warned that its presence adds very definitely to the dangers of her condition and throughout the pregnancy she should be under observation. Should the local and general symptoms point to degeneration of the fibroid a laparotomy should be done; as in Case I, a myomectomy may be possible but in most cases hysterectomy will be required.

If the tumour seems from its position to be likely to obstruct labour it may either be attacked early on, or the position explained to the patient and operation postponed until a viable child exists, when a Cæasarean section plus hysterectomy may be performed. The risks of this operation are not materially greater than those of a hysterectomy performed a month or two earlier and many women, when they understand that this is practically certainly the only chance they will ever have of giving birth to a living child, will choose to go on until near term.

If the fibroid is causing no symptoms and is not placed where 
it is likely to block the pelvis, the probability is that the labour will proceed more or less normally. The uterine contractions may be interfered with by the tumour, the first stage will probably be somewhat slow, instrumental help is more likely to be needed than if there were no fibroid, and I have had to remove the placenta manually in more than one case of this kind owing to the fibroid having interrupted the normal retraction of the uterus.

If the patient gets over the labour and the puerperium, what then? In the majority of cases I think operation should be advised. The last four cases illustrate some of the dangers of leaving a fibroid behind. Altered blood supply is more than likely to produce degenerative changes in the tumour, either necrobiotic or gangrenous. If the patient escapes this danger, the ordinary risks of a fibroid, such as excessive bleeding, remain and, as in Case V, the growth may become malignant.

It by no means follows that hysterectomy will be required. A fibroid which has permitted a pregnancy to proceed to term is likely to be nearer the serous than the mucous surface of the uterine wall and, if single, may be enucleated with ease and safety. The former fear of myomectomy is giving place to the conviction expressed by Christopher Martin in his Ingleby Lecture that myomectomy is the ideal treatment of uterine fibroids, and with increasing experience the proportion of cases so treated is likely to increase steadily. 